\title{
Informal settlements, the emerging response to COVID and the imperative of transforming the narrative
}

\author{
Amita Bhide ${ }^{1}$ (i) \\ Accepted: 14 October 2020 / Published online: 3 November 2020 \\ (c) Institute for Social and Economic Change 2020
}

\begin{abstract}
The COVID pandemic has exposed several faultlines of urbanism in India. This paper is a narrative of the remarkable continuities between the past legacies of governance of informal settlements, pandemic response and emerging ideas of alternate urbanisms and their inability to address issues of inequity, exclusion and vulnerability. The pandemic and the resultant situation exposes the limits of the current policies, programming linked to informal settlements, their imagination of informality and outlines the urgent need to escape the trap of bracketing of informal settlements as an 'issue' within itself delinked from the dynamic and ever-changing processes of urbanization through community led policy responses and effective local governance. In the absence of effective state response, informal settlements authored their own script of coping with the challenges thrown by the pandemic; their presence, participation and centrality in scripting future policies is a muchneeded transformation of the narrative.
\end{abstract}

Keywords Informal settlements $\cdot$ Indian cities $\cdot$ Pandemic governance $\cdot$ Politics of informality $\cdot$ Transformation

\section{Introduction}

The COVID pandemic has exposed several fault-lines of Indian urbanism. Even as we are flooded with webinars on post-COVID imaginations and imageries of alternate urbanisms, these narratives follow a predictable trajectory of labelling informal settlements as the breeding ground of COVID and undertaking a host of corrective actions that are not cognizant of the realities and vulnerabilities of these settlements. These emerging responses build on a pre-existing antagonistic relationship between settlers who are perceived to be 'anti' their own health and administrators acting in the interest of larger public health. The antagonism has its roots in past legacies of pro-poor governance characterized by selective attention to issues, overall neglect of living conditions, and a blinkered knowledge of informal settlements. The policy response to the pandemic could have been a potential opportunity to revisit these past patterns, understand the integral relationship between settlement

Amita Bhide

amita@tiss.edu

1 School of Habitat Studies, Tata Institute of Social Sciences, Mumbai, India 
formation and urbanization and address issues of vulnerability and inequity in a frontal manner. Instead, it has attenuated the vulnerabilities of the settlers and generated an ethos of fear and loss. Re-imaginations of the Indian city fail to show promise in this regard and some of them actively constitute new threats to settlements.

The paper is a narrative of this trajectory in which there are remarkable continuities in these past legacies, the evolving pandemic response and emergent ideas of alternate urbanisms in that all of them are unable to address fundamental issues that create informal settlements and perpetuate conditions of inequity, exclusion and vulnerability. While the basis for this paper is the experience of field interventions in informal settlements in Mumbai prior to and during the pandemic and the lockdown, it also draws from studies and experiences of such settlements in other Indian cities. Section 1 traces the past legacies of exclusion, Sect. 2 discusses the nature of data and knowledge of settlements, both of which produce peculiar features of pro-poor governance in our cities that are discussed in Sect. 3. Section 4 focuses on the evolving patterns of pandemic governance and the modes in which informal settlements authored their own patterns of coping with the challenges thrown by the same. The concluding section identifies the continuities and overlaps in the policy and governance narratives; the trap that politics of informality has bound us in and argues for a fundamental shift in narrative and adoption of an approach that accords a central role to informal settlers as co-creators of cities.

\section{Legacies of the past}

Slums or informal settlements have been recognized as a global challenge for some time now. ${ }^{1}$ In India and several other countries of the global south, such settlements represent a mode of urbanization, almost equal in significance (if not more) to urbanization occurring through formal processes of planning. Thus, even while there are issues of data definition and consequent non-inclusion of settlements in official data on slums; the census 2011 shows that 65.5 million people stayed in slums in the country, comprising 17.4 percent of the urban population of the country. While the phenomenon of settlement formation and existence has gained recognition in data and policy, the conditions of life in these settlements are characterized by insecurity and an underlying vulnerability to evictions, despite years of existence and efforts to consolidate the footholds in the city. Settlers also struggle with basic services such as water, sanitation, electricity and environmental risks associated with specific sites such as flooding, landslides and air pollution.

As per the Census 2011; 44 percent households live in a single room. 56.7 percent have water source within their premises while 66 percent of households in informal settlements have latrines within the premises. The National Family Health Survey 4 2015-16 (IIPS and ICF 2017) conducted a special study of living conditions and health in informal settlements in eight cities of the country. This study concludes that housing and environmental conditions, health services, and hence, the health status of women and children in informal settlements as indicated by stunting, anaemia and weight is significantly worse than in non-slum areas. The NFHS-4 also concludes that there are significant intra-city and intercity disparities in the living conditions in informal settlements. The socio-economic profile

\footnotetext{
1 The report of UNCHS 'The challenge of slums' in the year 2003 is an indication of this recognition; it has also been reflected in the MDGs and the SDGs adopted by the UN system.
} 
of settlers is a significant dimension of the vulnerability of informal settlements as well. More than 20 percent of the population in informal settlements belongs to scheduled castes (Census 2011). A recent survey in Bangalore indicates that more than 75 percent of the surveyed households in slums earned \$2 a day (Roy et al 2018). TISS survey of 20,000 households in M(East) ward in Mumbai reveals that the average earnings of informal settlers were half the city's average monthly earning of Rs 20,000 (TISS 2013). This indicates that there is a significant concentration of multidimensional poverty focused in informal settlements. Informal settlements to conclude are bundles of exclusions social, economic, spatial, political.

The hardest struggle that settlers face though, is with labels of encroachment, illegality and unauthorizedness - these create an extremely complex relationship with the institutions of the state and city politics. Such labelling leads to contested citizenships and rights (Holston 2008), a transverse relationship (Bhan 2017) with plans and adversarial and constantly shifting relationships with law and entitlements (Dutta 2012). Popular and patronage politics based on constituency building, award of selective benefits that entrench local politico-economic interests result in conditions of living that are not just poor but see little improvement over years.

The legacies of being neglected and patronized in urban policy, planning and governance run deep and are expressed in the contemporary conditions of living. The COVID19 pandemic exposed many of these fault-lines: informal settlements often emerging as hardest hit not just by the virus, but also by the lack of livelihood, and inability to protect themselves from the threat of infection due to inadequate water and sanitation, the absence of community spaces that could enable spaces for isolation, vulnerability to eviction and overcrowded housing.

\section{Knowledge of settlements: the blinkered eye}

While informal settlements have been part of Indian cities for the past fifty to seventy years; several issues plague the official knowledge of settlements and the consequent implementation of policies (Bhide and Wagle 2009). Overall, not a single city has a comprehensive knowledge of settlers, settlements, the living conditions within, the built assets and public resources created over a period of intervention and timelines when repairs or reconstruction to them might be needed. Planning of any kind - short term or long term is anathema to governing informal settlements and data as such is also collected, deployed and maintained with a blinkered eye that enables a knowledge of settlements that creates only part visibility and remains contested. A discussion of some of these issues follows:

a. Knowledge of informal settlements is linked to the 'legal' lens

Informal settlements are seen to disturb the 'order' of the city; their 'recognition' or 'denial of existence' is linked to slum legislations, administrative processes and resource commitments. Obtaining data of all existing settlements at a point in time has thus, been made obscure. There are several settlements that are 'not recognised' by city or state governments; in Bhubaneswar, for example, out of 436 settlements, 320 (73 percent) are unauthorized and 116 (27 percent) are authorized. The 2011 census made attempts to record 'settlements' by introducing a new category called 'identified slums'; the parameters for 
identified slums are however contested as they value what 'seems' informal rather than what 'is' informal.

\section{b. Knowledge of informal settlements is linked to purposes of governmentality}

Legal recognition and definitions are not the only barrier to knowledge of informal settlements. Over the years, settlements have become multi-generational. As settlements acquire a variety of meanings in relation to the local political economy, knowledge pertaining to informal settlements is also politically manoeuvered. Settlements can thus remain labelled as slums despite significant improvements in housing and infrastructure; they can be labelled slums though they may be created by the government. Some illustrations of such processes include: The census 2011 showing a sudden spurt in slum population across all cities in Andhra Pradesh. Similarly, Bjorkman (2014) cites the example of Shivajinagar, Mumbai, which was settled as a municipal colony in 1974 but continues to be marked as a slum. Slum has emerged as a manoeuverable spatial entity deployed for contingent interests. Another aspect of knowledge linked to governmentality has to do with the aspects which are sought to be known and aspects that remain invisible. Data on land ownership, number of houses is often collected while that on service access, vulnerabilities, livelihoods is not available with the local authorities. Knowledge of settlements is also fragmented across various departments and governance institutions, and there is very rarely any effort to converge and triangulate.

\section{c. Knowledge denies agency to settlers and is undemocratic}

A key attribute of the knowledge of informal settlements is that it is highly extractive in nature, collected and owned by outsiders (often consultants), very rarely placed in public domain and its use and application in decision-making remains uncertain. Its mode of collection, analysis, and form of reporting remains inaccessible to the settlers, even though it concerns their lives and decision-making about their destinies. Appadurai (2006) asserts that a 'right to research' is part of an essential repertoire of rights in an era of globalization. Such a right to research is essential to counter official knowledge and to assert alternate dimensions of realities.

The absence of democratized and accessible data meant that most city governments had no idea of the number of households in each area in the wake of the pandemic, they had no means to identify vulnerable households in the settlement nor did they have knowledge of which settlements required more support than others, or localities where water or sanitation facilities required urgent upgradation, or resources available in settlements that could be deployed in emergency situations. It resulted in significant wastage and misdirecting of resources while several settlements remained unreached.

\section{Governing informal settlements: emerging dimensions}

The last two decades have added new features to the governance of informal settlements. A key feature of informal settlements in Indian cities is the heterogeneity and yet continuity demonstrated in the composition and nature of settlements and policy responses to them. The heterogeneity has to do with the scale of the city and urbanization, nature of the land and labour markets, the fact that urban development and housing are state subjects, local 
social relations, power differentials and finally the city geography. While all informal settlements in all cities experience denial, insecurity and exclusion; these factors determine the particularities such as the degree and nature of exclusions, insecurity and denials experienced by settlers. In Mumbai, for example; more than half of the city population stays in informal settlements and local political economy accommodates free housing to eligible settlers within the city through private developers while Delhi as a capital city actively pursues a policy of state-led resettlement. The local state in Mumbai is far more privatized and expects inhabitants of resettled colonies to pay for all services unlike the local state in Chennai which takes a fair amount of interest in provision of services in resettlement colonies as well as settlements.

Issues of toilers and settlements are integrally connected and require redressal in an integrated manner. Contemporary policy discourse however acknowledges 'settlements' as a phenomenon while separating it from issues of livelihoods, poverty and vulnerability. This new discourse on one hand recognized the existence of settlements-beginning with including and measuring data on slums as part of the decadal census in 2001; introduction of housing schemes and basic services to settlements that were'recognized' and on-paper adoption of reforms that include a pro-poor budget, and services to informal settlements; on the other hand, this discourse perpetuated the legacy of displacing settlements for infrastructure or beautification schemes and enabled a shift of attention from issues of labour to issues of land. The focus on land rather than labour or toil has meant that even the fledgling institutional machineries of welfare in cities have been dismantled or restructured. Education, health, community development, poverty redressal are departments of local/state governments that are understaffed or under-resourced.

It sees formal housing provision, stripped of linkages to economic and developmental opportunities and health as forms of 'rehabilitation'. Coelho et al. (2020) point out how there has been an increased peripheralization of the poor through resettlement and lowincome housing programmes. New dimensions and aesthetics were thus, added to earlier patterns of inequity and denial of housing rights. These new dimensions include (a) shifting of burdens of health and education to the settlers themselves (b) retaining several of the risk features in siting of such housing while providing little infrastructure to offset the risks (c) distancing of the livelihoods and other opportunities for mobility. Several cities have also experienced displacement through considering settlers as ineligible for such schemes, or through imposition of conditions on sale or lease of tenements. New dimensions alleviate some of the earlier challenges faced by informal settlements such as those linked to housing insecurity and complete lack of basic services while new challenges linked to livelihoods, infrastructural inequities and heightened economic burdens have emerged and been intensified. The contemporary settler profile has also become more complex with these policy interventions with single migrants, tenants emerging as the even more vulnerable groups within the settlers.

\section{Informal settlements and the pandemic}

It is in the context of the conditions described above that the COVID-19 pandemic surfaced in Indian cities. Unlike other diseases such as tuberculosis or malaria which have been identified with the poor environmental conditions in informal settlements; COVID-19 first emerged among international travellers and was then transmitted to the informal settlements via front line workers and workers who serviced the elite residences. Yet very soon, 
the narrative that took grip was that informal settlements are the source for unbound multiplication of the virus, that it is these settlements with their dense conditions that posed a risk to cities. Steps were urgently needed to contain the virus within and prevent it from spreading elsewhere. It is this logic that permeated specific measures in lockdowns; the realization of the challenges and hardships that settlers would face in the wake of these came much later and steps taken to alleviate these hardships were too little and limited. The pandemic also stimulated a range of discourses and reimagination of informal settlements, and cities has been a significant strand of these. We explore three aspects of pandemic governance viz: (a) Steps for containment (b) the absence of caring state and (c) reimaginations of the city and emergent threats and the responses that it has generated among informal settlers with a focus on Mumbai. The experience of Mumbai suggests that in the absence of effective care and enhanced duress caused by the pandemic, informal settlers created their own modes of coping and attempted to redress their concerns in highly creative ways within the limitations of the resources they had access to.

\section{A. Containing the Virus or Constraining Lives?}

Informal settlements were identified as possible hotspots for the pandemic, even before actual evidence of the same emerged. Indorewala and Wagh (2020) assert that in Mumbai, 'the war against the virus was fought on the bodies and in the neighbourhoods of the poor'.

The entire strategy for containing the virus comprised lockdowns of all economic activities other than those identified as essential, highly state controlled diagnostic and treatment regime, declaration of containment zones where clusters of positive cases were found, imposition of even greater restrictions in these areas, and creation of quarantine and isolation centres. Each of these strategies added to the pre-existing and multiple burdens on settlers. For example, the lockdowns on streets meant that vendors could no longer operate; paratransit modes such as auto-rickshaws could not be operated, construction sites, informal factories could not operate. Service sector workers such as those working as domestic workers were not permitted to enter their places of work; waste recyclers were denied access to waste collection points. Prolonged loss of livelihoods first hit the daily wage workers, but its impact was gradually experienced by most settlers dependent on monthly incomes or even those engaged in more regular jobs.

Density is a basic attribute of informal settlements and several aspects of everyday life are woven around density. Several of these practices were threatened by the lockdown restrictions. In these settlements, staying outdoors is as much part of life as spending time home. Lockdowns expected families of 4-5 persons or more to stay indoors in tin-roofed houses of 8 by 10 feet in the height of summer. Given the reality that very few houses possess refrigerators, and the smallness of homes; large storage of grocery items, vegetables and meat is difficult, and hence, daily or alternate day shopping is a common practice in informal settlements. The closure of local markets dealt a blow to this practice. Many homes follow an activity pattern that keeps few family members in the house at all times. The constant presence of all family members at home at all times created new issues. Young girls and women in the reproductive age found it difficult to identify a space for change of menstrual cloth. The burdens on women increased due to demands of constant engagements by children and men who were at home. Further, even accessing the relief available from public distribution outlets or that distributed by non-governmental organizations meant moving out of the home. On the other hand, moving out and being on the street was considered a 'crime' as it created risk of spreading the virus, and hence, deserving of 
frequent and casual beatings by police who were brought in to discipline the informal settlements. Scant supportive infrastructure added to challenges of social distancing. In a context where most water and sanitation infrastructure is shared, distancing is a challenge, frequent hand washing an impossibility. Intra-city mobility, even after relaxation of lockdown conditions, continued the restrictions on public transport and paratransit modes, thereby increasing the challenges that informal settlements faced in accessing the city resources and resuming their livelihoods. An entire way of life that has depended on collectivity, multiple and negotiated uses of the street, dense and multiple physical interactions with other sections of city dwellers for its footholds was and is thus, at threat of being unravelled by the pandemic and associated disciplining measures (Bhide 2020).

While the focus on containment was vigorous, it was not accompanied by equally robust actions on the 'caring' front. The pandemic exposed the poor status of entitlements among the urban informals and the limited outreach of all welfare schemes for the urban poor, with a study showing that only 63 percent slum dwellers got access to extra ration and about 40 percent obtained access to cash transfers across Indian cities. (Kundu 2020). State and city governments, with very little data and knowledge of the settlements attempted to respond to emerging needs in a knee-jerk fashion without a comprehensive programme and with little preparedness. The 'care' of the state often appeared as a rhetoric while its disciplinary face was the most visible and experienced reality in informal settlements.

The overwhelming impact of the lockdown was a crisis of hunger, which was attempted to be met through a combination of food grain distributed via the public distribution system and the provision of cooked meals at some outlets. The response of governments to the issue of outreaching food and grain to migrant workers and informal settlements has been variable; with some states (Delhi, Kerala, Telangana) attempting to be more universal and others more restrictive (Maharashtra, Gujarat). The actual outreach of grains through public distribution system, however, has been singularly short in all cities. In Mumbai, the public distribution policies were particularly restrictive and a decision to serve only cooked meals to non-ration card holders, or some pre-packed ration kits via the corporate social responsibility (CSR) route provided some relief but failed to effectively deal with the crisis of hunger as it was supply-led.

The absence of effective primary health care institutions and mechanisms is an attribute of most Indian cities. In Mumbai, the public health care system at large and the primary health care system in particular has been a victim of austerity and neglect in the last few decades. The existing resources were so preoccupied with the containment of the pandemic that other health services were neglected. Meals, supplementary nutrition provided through anganwadis were closed down; other health services were absent. Consequently, several health ailments and needs-diseases such as tuberculosis, heart and kidney ailments, pregnancy and reproductive health needs, other fevers were neglected, and there were no avenues to redress the same. This added to the pressures experienced by inhabitants of informal settlements as these were the health needs that were of priority to them while COVID 19 represented just one more health threat.

The lack of a caring face of the state was demonstrated most sharply in the creation, location and operation of quarantine centres in Mumbai. The strategy of creating quarantine and care centres was a part acknowledgement of the dense living conditions in informal settlements and the consequent need to create separate facilities for care of high-risk contacts of positive cases and low-risk positive patients. However, the location of many of these centres is far from the settlements themselves, a legacy of spatial inequity and the absence of community infrastructure in the vicinity. Further, even when spaces such as marriage halls, banquet facilities, schools, vacant buildings have been taken over for such 
care centres; the standards of care have been quite poor. In Mumbai, some quarantine centres have been initiated in high pollution zones or in unoccupied slum rehabilitation buildings with incomplete infrastructure. The number of meals served, the quantity of food has been found to be wanting. As a result of the above conditions, the overall lack of constructive engagement and the compulsion about shifting to these centres away from caretaking families made quarantines jail—like and generated resentment among the inmates.

In opposition to the residents of formal buildings and elite areas; inhabitants of informal settlements were much more vulnerable to disease surveillance as they were considered 'high risk' while those in formal buildings could keep silent about the infection (Indorewala and Wagh 2020). Voluntary testing, disclosure and availability of treatment at affordable prices were not part of the choices available to residents of informal settlements where every strategy had an element of compulsion and was accompanied and executed by police along with health agencies. Quarantines, isolation centres and the overall containment strategy thus become part of the legacy of antagonism between informal settlements and the state rather than the exposition of the caring face of the state.

\section{B. Community-led responses to the pandemic}

The period between March-August 2020 was a particularly harsh period for informal settlers in India and in Mumbai. The state response not only did little to address the challenges faced by the settlers, but it added to their burdens through the highly disciplinary and constantly shifting policies. Several informal settlements demonstrated considerable grit, resistance, creativity, mutuality and caring in their response to the challenges thrown by the pandemic. One incident that has stuck in memory is that of a woman street vendor from Lallubhai Compound in Mankhurd who valiantly opposed the police who were confiscating her vegetables during the lockdown, there was no life without livelihood in the city and defending the same was an assertion of her right. While this was an outright defiance of state policy, in many settlements the local residents enclosed their own lanes, and restricted entry and exit. In others, volunteers mobilized residents in following social distance and queues for collecting water at public stand-posts or for ration distribution. Food was mobilized from nearby eating establishments for 350 migrant workers in recycling shops in Mandala when their employers absconded and hunger became a real crisis. Community kitchens which used the energies of local youth were able to provide fresh food to families in time. Local madarasas gave space to run community quarantine centres is a number of settlements. In the M(East) ward where I work, there was no dearth of volunteers to work in communities, attend to essential needs; there was a significant mobilization of resources within in the form of spaces, collecting data, coordinating with local elected representatives. The major challenge was in creating a space for the voice of these communities, their work and their contribution to be acknowledged. Places where such contribution was acknowledged like in Dharavi emerged as success stories in effectively arresting the unrestricted spread of the virus and containing mortality.

\section{Reimaginations of the Indian City}

The pandemic has given rise to a lot of thought churning among various sections of society about the nature of our cities, the modes of resurrecting them or even reimaging the same. One of the significant thematics in this re-imagination is around informal settlements and their place in Indian cities. Some of the narratives around which such re-imagination 
is clustered are: (a) Indian cities should work towards becoming less dense, more environment-friendly and green (b) informal settlements are vulnerable but also a risk to the city (c) There should be an attempt to replace informal settlements and minimize their presence through provision of affordable housing. Such narratives have remarkable continuity with past narratives of slum-free cities, and world-class cities. When accompanied with real estate sector and housing being perceived as the most probable modes of reviving an economy on a downward spiral; the continuity with these past narratives which have resulted in creating peripheral, low-quality, high density and vertical slum-like housing for dwellers of informal settlements becomes more sharp and clear.

There are very few assertions discussing the improvement of health, education and community infrastructure in informal settlements, enhancing public space in our cities, or the need for improving the state of pro-poor governance at large. Another missing piece in the emergent narratives is discussion around enhancing working conditions of informal workers and challenges of scaling up of marginal enterprises. Most importantly, while several alternative forms of urbanism are being explored; its faultlines such as the inability to take the informal settlers and workers along as partners are hardly a subject of discourse. This generates apprehensions that even the so called 're-imaginations' would turn out to be recasts of the exclusionary trends experienced in Indian cities in the recent past with some token inclusive measures.

\section{Conclusion}

The past approach towards informal settlements was characterized by a combination of patronage and neglect, insecurity and inequity. This was accompanied by a blinkered approach to data and knowledge of settlements. Recent years have witnessed an intense focus on land and housing and a bypassing of issues of labour, welfare and addressing poverty. These three factors together accompanied by a denial of participation of settlers have created conditions by which informal settlements in Indian city continue to be bundles of exclusions.

A humane policy response in the wake of a crisis like COVID-19 could potentially have been an opportunity to begin such a process towards more equitable cities but shows all signs of missing the same. Instead the pandemic and the associated measures of containment resulted in an unravelling of the 'usual 'practices of living, working in the Indian city and unleashed an ethos of loss, hunger and fear in informal settlements in particular. The patchy state of pro-poor governance during the pandemic in which the caring face of the state was overshadowed by the disciplining face added to the vulnerabilities. In exceptional cases like Dharavi wherein the adoption of a caring face, a proactive community outreach and partnership with local communities and organizations created effective responses for containment of the pandemic. In fact, cases like these demonstrate the potential of "what can happen' if effective partnerships with informal settlements are forged.

The emergent re-imaginations of Indian city and urbanism have remarkable continuities with previous discourses of slum-free cities and a lack of critical inquiry of the existing patterns of urbanism that generate such exclusion and inequities. The ongoing and continuous discourse around settlements brackets the phenomenon, labels it as a problem and seeks to take corrective action vis-vis select aspects of the same. However, a non-acknowledgement of the vexed and mutually constitutive relationship between the nature of urbanism and the nature of informal settlements results in cosmetic changes in the situation, 
while being unable to make a dent in reproduction of the process in newer places, scales and forms. Such a bracketing of informal settlements does not bode well for reduction in vulnerabilities and increase in resilience of cities in the near future. There is an imperative to open up such brackets, recognize the integral relationship and contribution of informal settlements and economy to the nature of urbanism, and attempts made to understand the conditions of life; and redress the vulnerability of these settlements. Cases like Dharavi indicate the potential of such partnerships. The voice and agency of informal settlers need to be accorded a central place in city policy and governance; they need to be essential partners in the determination of the city futures, as it is only their participation that can ensure that the fault-lines and antagonism discussed earlier can be countered effectively. The coproduction of data, knowledge and participation in policy-making and governance are the key pointers of more inclusive and resilient cities in India.

\section{References}

Appadurai A (2006) The right to research. Glob Soc Edu 4(2):167-177

Bhan G (2017) From the basti to the house: socio-spatial readings of housing policy in India. Curr Sociol 65(4):587-602

Bhide A, Wagle S (2009) Situation analysis of pro-poor governance in Pune. Unpublished research report Tata Institute of Social Sciences, Mumbai, Nagpur and Bangalore

Bhide A (2020) Unfolding of lockdown disaster: from the perspective of M(East) ward. Obs Res Forum

Bjorkman L (2014) Becoming a slum: from municipal colony to illegal settlement in liberalisation era Mumbai. Int J Urban Reg Res 38(1):36-59

Census (2011) Primary census abstracts, registrar general of India, ministry of home affairs, government of India, Available at: http://www.censusindia.gov

Coelho K, Mahadevia D, Williams G (2020) Outsiders in the periphery: studies of peripheralisation of low income housing in Ahmedabad and Chennai. Int J Hous Policy, India. https://doi.org/10.1080/19491 247.2020.1785660

Dutta A (2012) The illegal city: space, law and gender in a Delhi squatter settlement. Ashgate

Holston J (2008) Insurgent citizenship: disjunctions of democracy and modernity in Brazil. Princeton University Press, Princeton

IIPS and ICF (2017) National family health survey 2015-16: India. Indian Institute of Population Studies, Mumbai

Indorewala H, Wagh S (2020) How strong is the link between Mumbai's slums and the spread of the corona virus. Scroll

Kundu D (2020) Rapid assessment of impact of COVID 19 on lives and livelihoods of Slum dwellers in Indian cities. Unpublished report of webinar 28 May 2020. NIUA and World Vision, New Delhi

Roy D, Palavalli B, Menon N, King R, Pffefer K, Lees L, Sloot P (2018) Survey based socio-economic data from slums in Bangalore. Sci Data 5:170200. https://doi.org/10.1038/sdata.2017.200

Tata Institute of Social Sciences (2013) Socioeconomic conditions and vulnerabilities in M(East) ward. Unpublished research report, TISS, Mumbai

UNCHS (2003) The challenge of slums: global report on human settlements. UNCHS and Earthscan

Publisher's Note Springer Nature remains neutral with regard to jurisdictional claims in published maps and institutional affiliations. 